\title{
Review of PTB Measurements on Emissivity, Reflectivity and Transmissivity of Semitransparent Fiber-Reinforced Plastic Composites
}

\author{
A. Adibekyan ${ }^{1}$ - E. Kononogova ${ }^{1}$. C. Monte ${ }^{1} \cdot$ J. Hollandt ${ }^{1}$
}

Received: 13 October 2017 / Accepted: 27 February 2019 / Published online: 12 March 2019

(c) The Author(s) 2019

\begin{abstract}
Due to several excellent material properties, fiber-reinforced plastic (FRP) composites are expediently used in many applications, e.g., in the field of renewable energy and in oil, gas, and transportation applications. They show excellent mechanical stability, low weight and fatigue, and high corrosion resistance. However, their full potential for exploitation, as well as the lifetime of FRP-based structures, is limited due to certain defects and damage mechanisms. One of the most important methods used to ensure the quality of FRPs is non-destructive testing and active thermography. A prerequisite for quantitative active thermography is accurate knowledge of the optical properties of the investigated material (i.e., its spectral emissivity, reflectivity, and transmissivity). The objective of PTB as a partner organization within the European EMRP project titled "Validated Inspection Techniques for Composites in Energy Applications" was to improve the state of the art of this technique. One of the goals in doing so was to significantly reduce the uncertainty of emissivity measurements of FRP materials in the visible and infrared wavelength ranges. Achieving a target value of lower than 0.01 of the emissivity of partially transmitting materials is very challenging, especially at temperatures close to room temperature. Different experimental setups at PTB were employed for these measurements: one setup for spectral emissivity measurements in air and the other for diffuse reflectivity and transmissivity measurements. In this paper, we give a review of PTB measurements on emissivity, reflectivity and transmissivity of semitransparent FRP composites. Part of this work has already been published in Adibekyan et al. (emissivity, reflectivity and transmissivity of semitransparent fiber-reinforced plastic composites. https://www.ndt.net/article/dgzfp-irt-2017/ papers/17.pdf, 2018). Here, we present the complete set of data for seven technical relevant materials and compare the results. The directional spectral emissivity was determined at a nominal sample temperature of $40{ }^{\circ} \mathrm{C}$, at angles of observation from $10^{\circ}$ to $70^{\circ}$ with respect to the surface normal and in a wavelength range from $5 \mu \mathrm{m}$ to $25 \mu \mathrm{m}$. In addition, these spectrally and directionally resolved measurements allow to calculate the total directional emissivity and the hemispherical emissivity. For the
\end{abstract}

Extended author information available on the last page of the article 
determination of the directional-hemispherical spectral transmissivity and directional-hemispherical spectral reflectivity a gold-coated integrating sphere and a vacuum FTIR spectrometer were used. The directional-hemispherical spectral transmissivity was measured under an angle of incidence of $0^{\circ}$; the directional-hemispherical spectral reflectivity was measured under an angle of incidence of $10^{\circ}$. These investigations were performed in the spectral range from $1.0 \mu \mathrm{m}$ to $16.7 \mu \mathrm{m}$ and compared in the overlapping wavelength range; the emissivity measurements were performed using the setup for spectral emissivity.

Keywords Emissivity $\cdot$ Fiber-reinforced plastic $\cdot$ Reflectivity $\cdot$ Semitransparent materials $\cdot$ Transmissivity $\cdot$ Uncertainty $\cdot$ VITCEA

\section{Introduction}

The excellent mechanical properties, low weight and fatigue, and corrosion resistance of FRP composites lend weight to their potential for use in the field of renewable energy, and in oil, gas, and transport applications [1]. These advantages make FRPs significant for reducing greenhouse gas emissions and reliance on fossil fuels. However, the full exploitation of this potential is hindered by the diverse range of defects and damage mechanisms that reduce the strength, stiffness, and lifetime of FRP structures. Within the scope of the EMRP Project titled "Validated Inspection Techniques for Composites in Energy Applications" (VITCEA) [2-5], traceable procedures were developed and validated for innovative non-destructive testing (NDT) techniques and applied to selected fiber-reinforced plastic (FRP) composite materials exhibiting different kinds of defects. As one of the partner organizations within this project, PTB defined optical properties of FRP materials (i.e., spectral emissivity, reflectivity, and transmissivity) for active thermography, which is one of the most important methods used to ensure the quality of FRPs.

To date, these optical properties of FRP materials have not been sufficiently investigated. Even handbooks detailing the characteristics and properties of FRP composites do not provide sufficient or accurate information about their spectral emissivity, reflectivity, or transmissivity [1]. Furthermore, the emissivity measurements of the FRPs are usually performed indirectly via reflectivity values using an FTIR spectrometer [6] or industrial reflectometers [7], often without taking into account the uncertainty budget according to the Guide to the Expression of Uncertainty in Measurement (GUM) [8]. Moreover, the target uncertainty of less than 0.01 declared in the VITCEA project is currently around the level of accuracy in the state-of-the-art emissivity measurements of opaque materials, when measured at relatively high temperatures. Direct emissivity measurements performed at temperatures close to room temperature of partially transmitting FRP materials, which have a low thermal conductivity, represent a new challenge.

Different setups were employed for these measurements at PTB: one setup for spectral emissivity measurements in air and the other for diffuse reflectivity and transmissivity measurements. 


\section{Experimental Setups}

PTB routinely determines the emissivity of a wide range of materials using two setups: the Reduced Background Calibration Facility (RBCF) for measurements under vacuum $[9,10]$ and the Emissivity Measurement in Air Facility (EMAF) [11]. The operation principle of both setups is similar and based on the direct radiometric method, which relies on comparing the spectral radiance of an investigated sample with two variable-temperature blackbodies as reference standards of radiation temperature. It provides traceability to the International Temperature Scale of 1990 (ITS-90) and, in combination with the precisely evaluated radiation budget, it also provides wellestablished uncertainties of 0.005 and better. Calculation of the spectral distribution of uncertainty is based on the GUM and performed for each individual measurement [12].

Both setups were also used within the scope of the VITCEA project to perform high-accuracy emissivity measurements of the FRP materials. The RBCF was used solely to measure internal reference samples that were applied to verify the uncertainty of the EMAF. All direct emissivity measurements shown below were recorded with the EMAF. These measurements were performed in the range from $5 \mu \mathrm{m}$ to $25 \mu \mathrm{m}$, at a nominal temperature of $40^{\circ} \mathrm{C}$, and at angles of observation from $10^{\circ}$ to $70^{\circ}$ with respect to the surface normal. The total directional emissivity and the hemispherical emissivity were calculated as well.

The direct emissivity measurements in the wavelength range below $5 \mu \mathrm{m}$ require a significantly higher temperature of the samples because of Planck's law. However, the GFRP and CFRP samples investigated are not suitable for operation at high temperatures. Therefore, a different approach was chosen to perform the measurements in the range from $1 \mu \mathrm{m}$ to $5 \mu \mathrm{m}$ in which a setup for diffuse reflectivity and transmissivity measurement was used. Using a gold-coated integrating sphere and a vacuum FTIR spectrometer (Fig. 1), this setup allows optical properties to be determined in the NIR and MIR ranges at a temperature of $25^{\circ} \mathrm{C}$. A Globar or tungsten-halogen lamp serves as a source of radiation. The reflected or transmitted radiation is recorded with an MCT detector. Each sample was subsequently placed in the integrating sphere-either at the transmissivity port, allowing the directional-hemispherical spectral transmissivity to be measured under an angle of $0^{\circ}$, or at the reflectivity port, allowing the directional-hemispherical spectral reflectivity to be measured under an angle of $10^{\circ}$.

The reflectivity and transmissivity were determined within the VITCEA project not only from $1 \mu \mathrm{m}$ to $5 \mu \mathrm{m}$, but in an extended wavelength range up to $16.7 \mu \mathrm{m}$ to obtain additional information about the investigated GFRP and CFRP samples. This allowed the emissivity calculated from these measurements to be compared with the direct method in the wavelength range up to $16.7 \mu \mathrm{m}$ (Sect. 4.3).

To characterize the integrating sphere and determine an uncertainty for the diffuse transmittance and reflectance measurements, different aspects of the setup were investigated: the systematic deviation and repeatability of the maximum signal; the background level; the successive attenuation of the incident flux level; the nonlinearity in the MIR and NIR ranges; and the sensitivity of the integrating sphere measurements to a potentially wide angular distribution of the diffusely transmitted radiation [13]. 


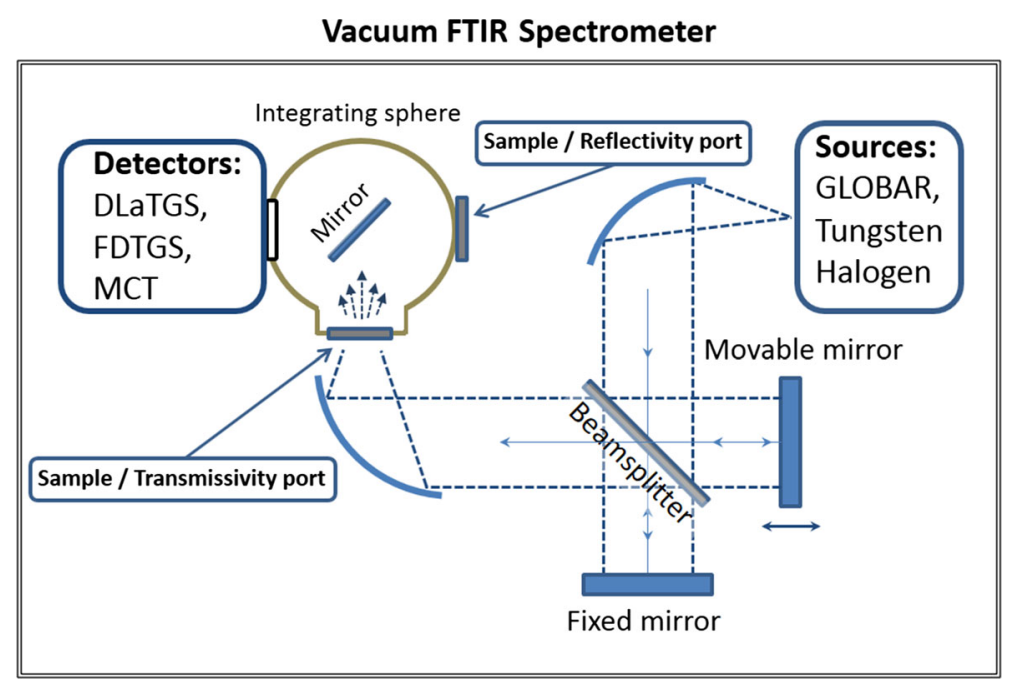

Fig. 1 Schematic presentation of the FTIR spectrometer with the integrating sphere

\section{Design and Composition of Reference FRP-Samples}

Several glass fiber-reinforced plastic (GFRP) and carbon fiber-reinforced plastic (CFRP) samples were prepared using different matrix materials (epoxy and polyamide) and different fiber orientations (bi-directional, unidirectional, and quasi-isotropic) for the individual fiber layers; the samples were prepared without and with preimpregnation. Basic information about the design and structural composition of the reference samples provided by the partner organizations in the VITCEA project is listed in Table 1. The detailed properties, including different types of defective artefacts, can be found in [4]. The thickness of each sample is $5 \mathrm{~mm}$.

\section{Experimental Determination of Optical Properties of Composite Materials}

\subsection{Transmissivity, Reflectivity, and Emissivity Data from $1.0 \mu \mathrm{m}$ to $16.7 \mu \mathrm{m}$}

The optical properties measured for all GFRP and CFRP samples investigated in the range from $1.0 \mu \mathrm{m}$ to $16.7 \mu \mathrm{m}$ are presented in Figs. 2, 3 and 4 with their calculated standard uncertainties. Three of the samples-GFRP PA12, GFRP QUADRAXIAL, and GFRP 913 CROSSPLY 0-90-show significant transmittance in the range from $1.0 \mu \mathrm{m}$ to $2.3 \mu \mathrm{m}$ (Fig. 2, highlighted in bold). The other four samples-CFRP SE84 CROSSPLY, CFRP SE84, GFRP MTM28+-55, and CFRP SE84 QI-show no transparency over the whole spectral range. The measurements of the directional-hemispherical spectral transmissivity were performed at a temperature of $25^{\circ} \mathrm{C}$ and for an angle of observation of $0^{\circ}$ with respect to the surface normal. The standard uncertainty is shown as shaded area around the curves. 


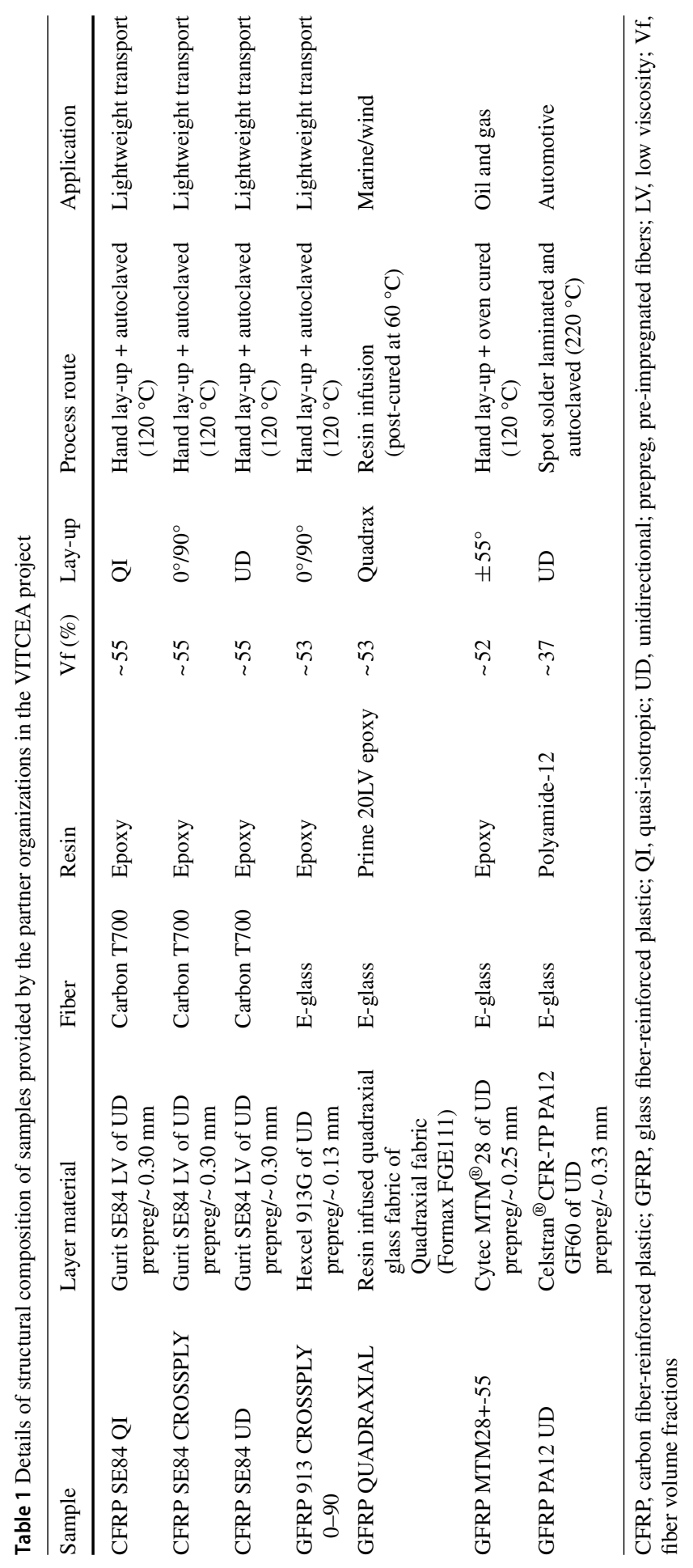




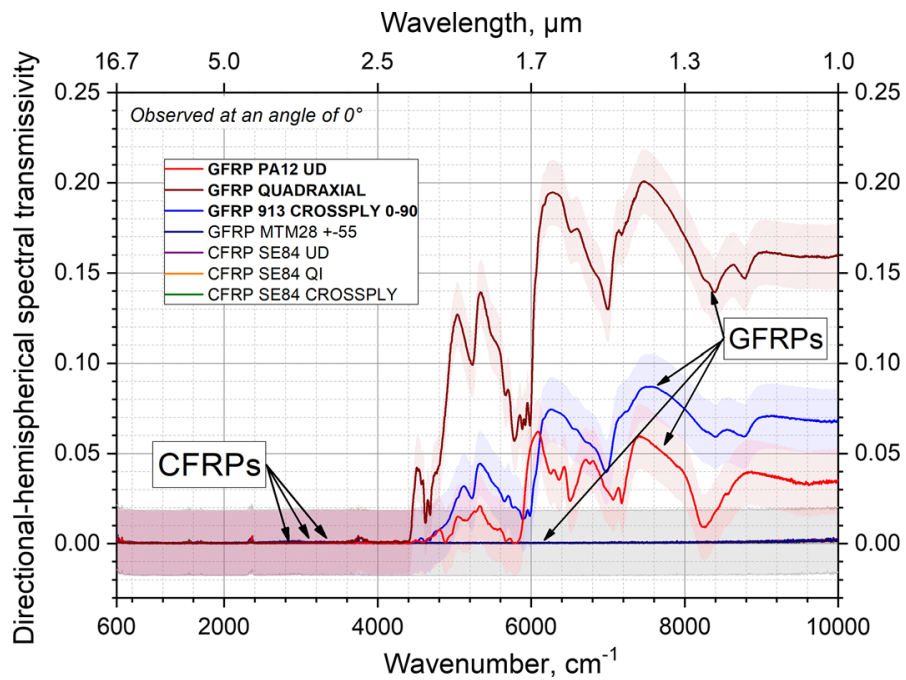

Fig. 2 The directional-hemispherical spectral transmissivity of all GFRP and CFRP samples investigated, measured at an angle of observation of $0^{\circ}$ with respect to the surface normal and at a temperature of $25^{\circ} \mathrm{C}$. In addition, the standard uncertainty is shown as a shaded area around the curves. The three partially transparent samples-GFRP PA12, GFRP QUADRAXIAL, and GFRP 913 CROSSPLY 0-90_-are highlighted in bold in the legend

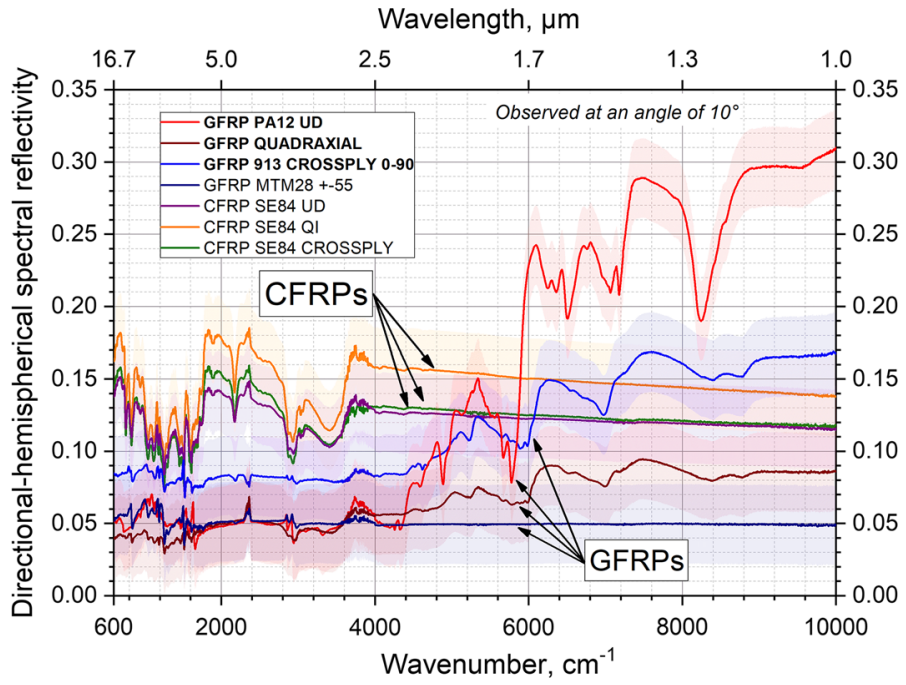

Fig. 3 The directional-hemispherical spectral reflectivity of all GFRP and CFRP samples investigated, measured at an angle of observation of $10^{\circ}$ with respect to the surface normal and at a temperature of $25{ }^{\circ} \mathrm{C}$. In addition, the standard uncertainty is shown as a shaded area around the curves and the three partially transparent samples_-GFRP PA12, GFRP QUADRAXIAL, and GFRP 913 CROSSPLY 0-90-are highlighted in bold in the legend

The resulting directional-hemispherical spectral reflectivities - also measured at a temperature of $25^{\circ} \mathrm{C}$-are depicted in Fig. 3. Here, the reflectivities are observed at an 


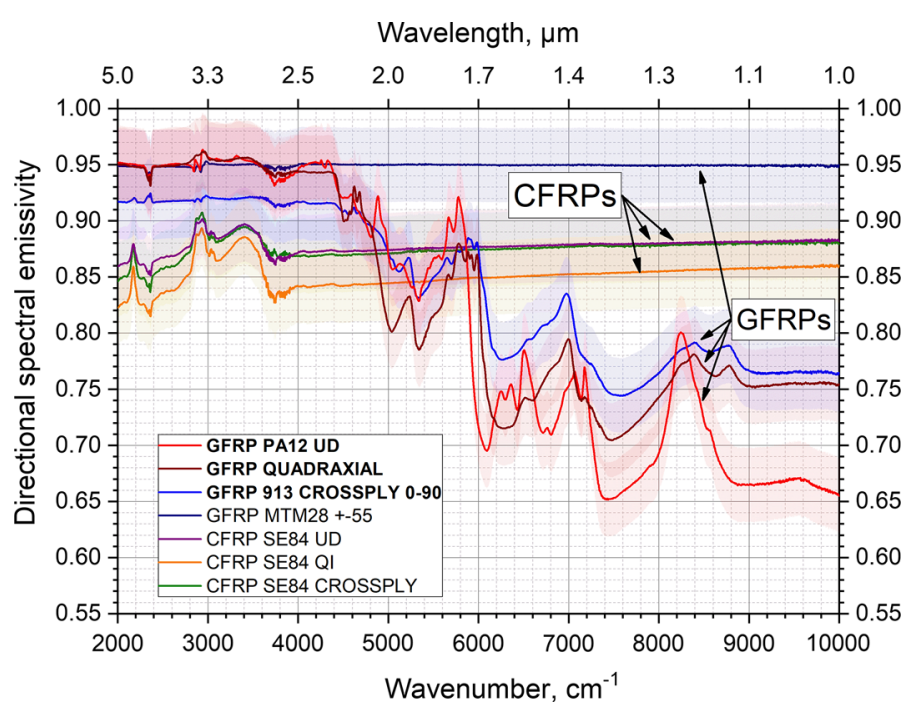

Fig. 4 The directional spectral emissivity of all GFRP and CFRP samples investigated, calculated from the transmissivity and reflectivity measurements presented in Figs. 2 and 3. Again, the combined standard uncertainty is shown as a shaded area around the curves and three partially transparent samples-GFRP PA12, GFRP QUADRAXIAL, and GFRP 913 CROSSPLY 0-90-are highlighted in bold in the legend

angle of $10^{\circ}$ and surrounded by a shaded area, which is also the range of the standard uncertainty. A certain structure at wavelengths below $2.3 \mu \mathrm{m}$ can be identified for the three partially transparent samples, whereas the other four materials show smooth reflectivity curves in this range.

As previously noted, the directional spectral emissivity in the range from $1.0 \mu \mathrm{m}$ to $16.7 \mu \mathrm{m}$ is calculated from the transmissivity (Fig. 2) and reflectivity (Fig. 3) measurements. In Fig. 4, the three partially transparent samples-GFRP PA 12, GFRP QUADRAXIAL, and GFRP 913 CROSSPLY 0-90- show not only a significant structure in their spectrally resolved emissivity values, but also a decrease in their emissivity at wavelengths below $2.3 \mu \mathrm{m}$. A relatively constant emissivity can be seen in the other materials. Figure 4 shows the calculated emissivity up to $5 \mu \mathrm{m}$. The calculated emissivities at longer wavelengths will be presented in Sect. 4.3 and compared with direct measurements in the overlapping range.

\subsection{Directional Spectral Emissivity Data from $5 \mu \mathrm{m}$ to $25 \mu \mathrm{m}$}

The measurements of the directional spectral emissivities were directly performed in the range from $5 \mu \mathrm{m}$ to $25 \mu \mathrm{m}$ and at a nominal temperature of $40^{\circ} \mathrm{C}$ at the EMAF. A slightly higher temperature of $40{ }^{\circ} \mathrm{C}$ instead of $25^{\circ} \mathrm{C}$ was chosen to increase the radiation originating from the sample and, by this, to reduce the uncertainty of the measurements. A potential temperature dependence of the emissivities can be neglected in this small temperature range between $25^{\circ} \mathrm{C}$ and $40{ }^{\circ} \mathrm{C}$. The wavelength range of these measurements was limited to $5 \mu \mathrm{m}$ due to the consequence of Planck's law: 


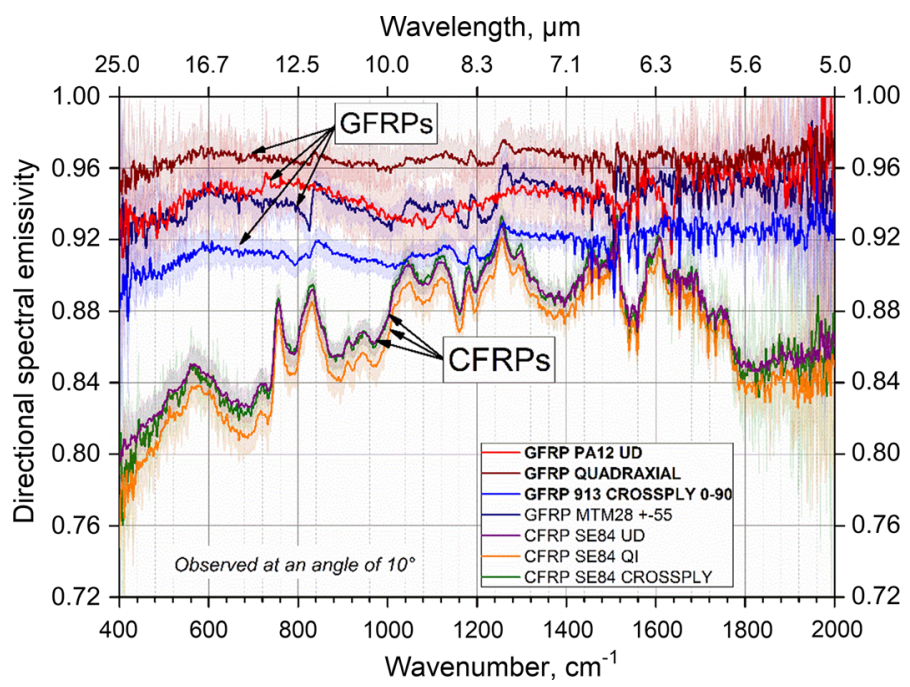

Fig. 5 The directional spectral emissivity of all GFRP and CFRP samples investigated at a nominal temperature of $40{ }^{\circ} \mathrm{C}$ and for an angle of observation of $10^{\circ}$ with respect to the surface normal. In addition, the standard uncertainty is shown as a shaded area around the curves

$5 \mu \mathrm{m}$ is the shortest wavelength that provides a sufficient signal for direct emissivity measurements around room temperature. The directional spectral emissivities of all GFRP and CFRP samples investigated at a nominal temperature of $40{ }^{\circ} \mathrm{C}$ and for an angle of observation of $10^{\circ}$ with respect to the surface normal can be seen in Fig. 5.

Furthermore, the EMAF provides measurements under the following angles of observation with respect to the surface normal of the samples: $10^{\circ}, 20^{\circ}, 30^{\circ}, 40^{\circ}, 50^{\circ}$, $60^{\circ}$, and $70^{\circ}$. A subsequent spectral and angular integration allow the total directional emissivities, the hemispherical emissivities, and their absolute standard uncertainties to be calculated.

In this article, the CFRP SE84 CROSSPLY and GFRP 913 CROSSPLY 0-90 samples were chosen as two examples of the angle-resolved spectral emissivity measurements of carbon and glass materials. The resulting spectral curves under different angles of observation are plotted in Figs. 6 and 7. Some of the angles measured have been omitted for the sake of clarity in the figures. The decrease in the directional spectral emissivities with increasing angles of observation, which is typical of highemission samples, is clearly visible.

\subsection{Total Directional and Hemispherical Emissivity Data}

The integrated quantities (the total directional and hemispherical emissivities) in the wavelength range from $5 \mu \mathrm{m}$ to $25 \mu \mathrm{m}$ and at a nominal temperature of $40{ }^{\circ} \mathrm{C}$ with their standard uncertainties are listed in Table 2 and plotted in Fig. 8. Since many components of the uncertainty budget of emissivity measurements depend on the measurement conditions and optical properties of the sample, the uncertainty is cal- 


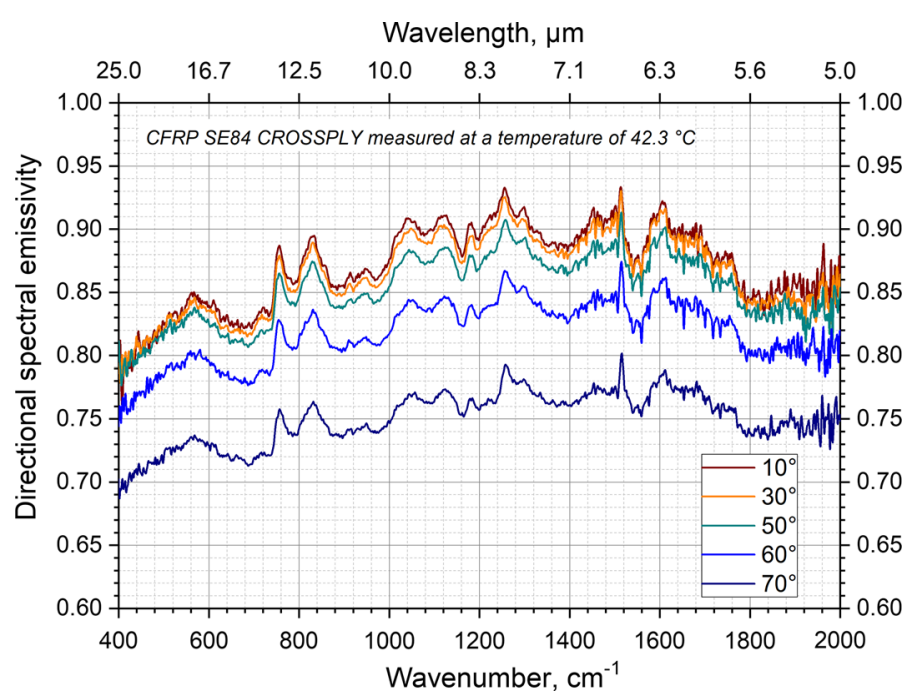

Fig. 6 The directional spectral emissivity of the CFRP SE84 CROSSPLY sample measured at a temperature of $42.3{ }^{\circ} \mathrm{C}$ and for angles of observation from $10^{\circ}$ to $70^{\circ}$ with respect to the surface normal

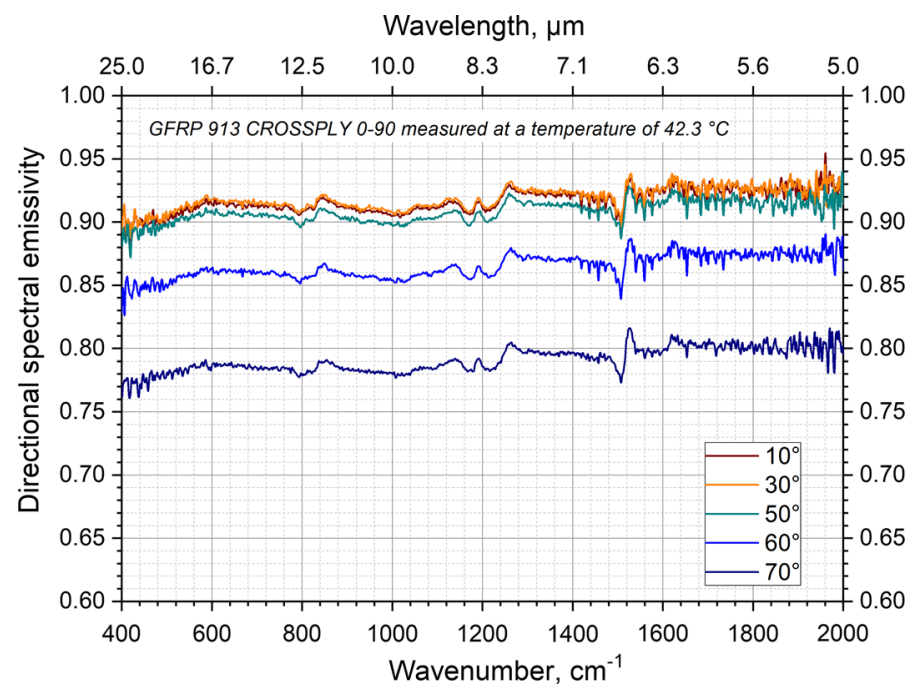

Fig. 7 The directional spectral emissivity of the GFRP 913 CROSSPLY 0-90 sample measured at a temperature of $42.3{ }^{\circ} \mathrm{C}$ and for angles of observation from $10^{\circ}$ to $70^{\circ}$ with respect to the surface normal

culated for each specific condition as well as for each individual measurement [12].

About half of the measured data presented in Table 2 meets the initial target of an uncertainty of less than 0.01 , while the other uncertainties are close to it. Given the current data situation for optical properties of FRP composites, this represents a significant improvement, allowing an improved evaluation of active thermography results [14]. 


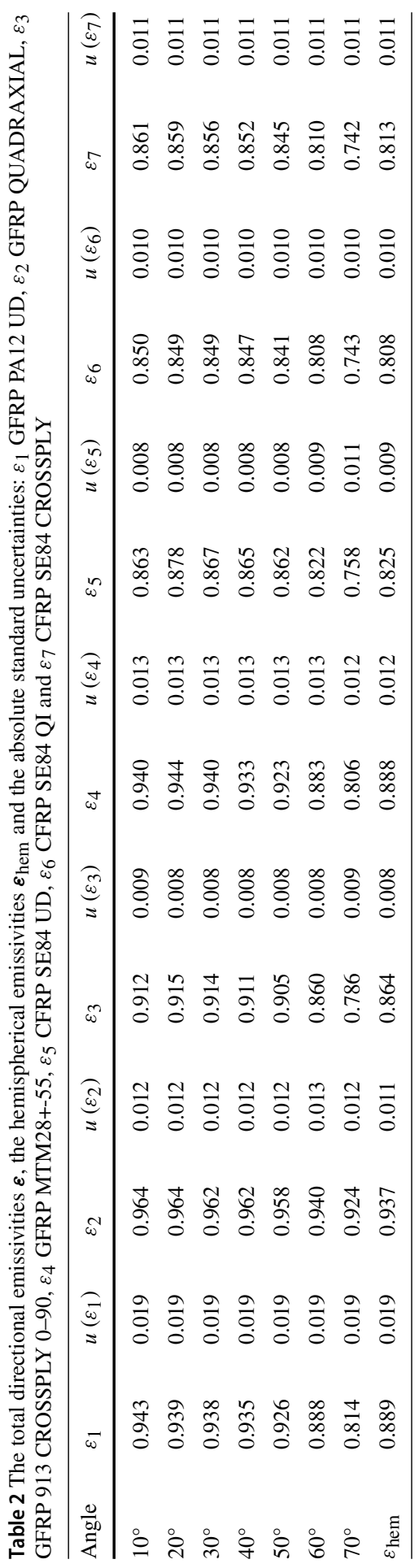




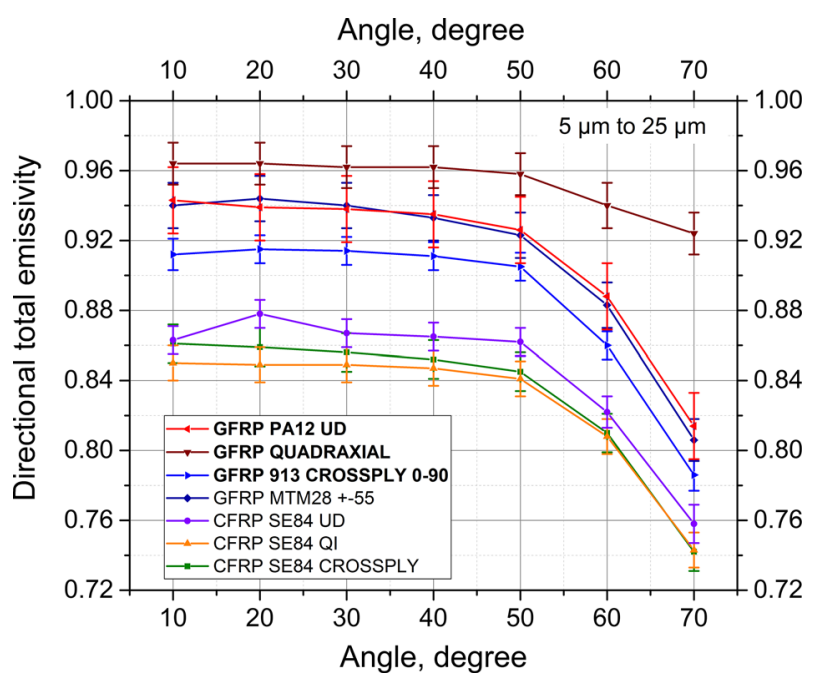

Fig. 8 Directional total emissivities of the materials investigated in the wavelength range from $5 \mu \mathrm{m}$ to $25 \mu \mathrm{m}$ and at a nominal temperature of $40^{\circ} \mathrm{C}$ with their corresponding standard uncertainties

Based on these results, it can be concluded that the emissivity of FRP composites depends mainly on the type of fiber material: the materials made of GFRPs in the wavelength range from $5 \mu \mathrm{m}$ to $25 \mu \mathrm{m}$ have a higher and spectrally less structured emissivity than the materials made of CFRPs. The angular dependence of all the samples is approximately the same; only the GFRP QUADRAXIAL, which has the highest emissivity, has a less pronounced decrease in the directional total emissivities with increasing angles of observation (Fig. 8). No influence of the fiber orientation or changes in optical properties depending on the orientation of the sample in the plane perpendicular to the optical path were revealed.

\subsection{Comparison of the Two Methods}

To ensure the consistency of our results, we compared the emissivities obtained by direct emissivity measurements (EMAF) with those obtained by the indirect approach (when calculated from transmissivity and reflectivity).

The results for two samples-GFRP PA 12 UD and CFRP SE84 CROSSPLY - are shown in Fig. 9. The very good consistency of the directional spectral emissivity for an angle of observation of $10^{\circ}$ in the overlapping wavelength range (from $5 \mu \mathrm{m}$ to $16.7 \mu \mathrm{m}$ ) within the range of uncertainty of both measurements illustrates the ability to correctly determine emissivities in a broad wavelength range.

Two advantages of the direct method are its ability to determine the total and spectral quantities in an angularly resolved way and the fact that possible warming effects of the sample can be properly considered, yielding results with low uncertainties in the longer wavelength range (Table 2 and Fig. 8). The indirect method (calculating the emissivity from the measured directional hemispherical reflectivity and transmissivity) yields a higher uncertainty in our setup and can be performed only using a specific 


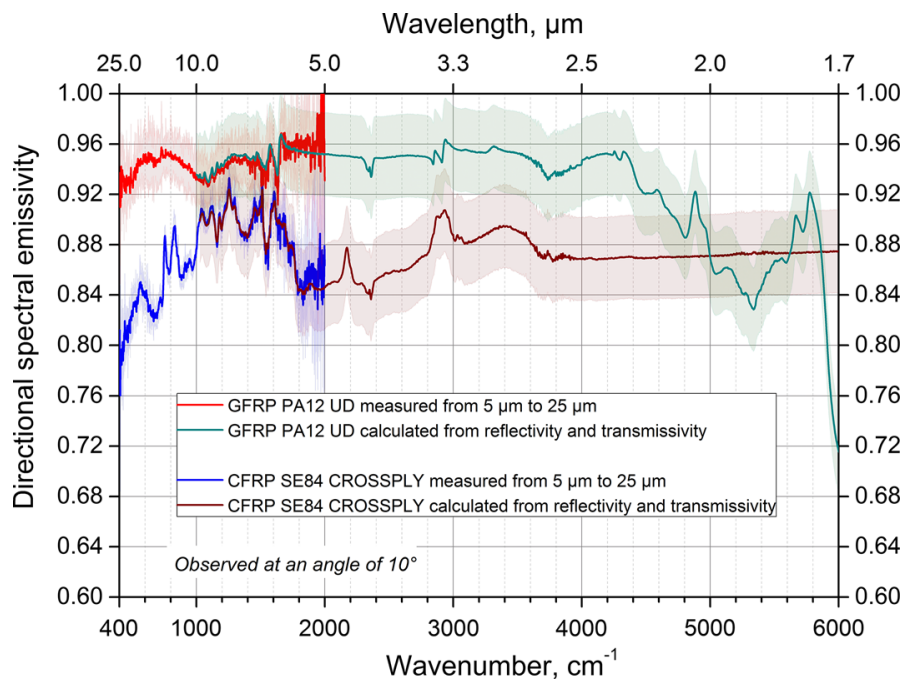

Fig. 9 Comparison of two methods used to determine the directional spectral emissivity for an angle of observation of $10^{\circ}$. This comparison shows the very good consistency of both measurement schemes for emissivity. Two samples-GFRP PA 12 UD and CFRP SE84 CROSSPLY - were chosen. In addition, the standard uncertainty is shown as a shaded area around the curves

geometry of incidence of the radiation. However, it allows the optical properties of FRP materials to be determined at room temperature in the range from $1 \mu \mathrm{m}$ to $5 \mu \mathrm{m}$.

\section{Summary}

The optical properties of samples made of CFRP and GFRP were experimentally determined at PTB using two different measurement setups: the emissivity measurement in air facility and the integrating sphere-based setup for diffuse reflectivity and transmissivity measurements. The directional spectral emissivity was directly measured at a nominal sample temperature of $40^{\circ} \mathrm{C}$, angles of observation from $10^{\circ}$ to $70^{\circ}$ over a wavelength range from $5 \mu \mathrm{m}$ to $25 \mu \mathrm{m}$ with very small uncertainties.

The directional-hemispherical spectral transmissivity and directional-hemispherical spectral reflectivity were determined over a wavelength range from $1.0 \mu \mathrm{m}$ to $16.7 \mu \mathrm{m}$ and were used to calculate the directional spectral emissivity in this spectral range as well. A comparison of the two methods used to determine the emissivity in the overlapping wavelength range (from $5 \mu \mathrm{m}$ to $16.7 \mu \mathrm{m}$ ) showed a very good consistency within the range of uncertainty of both measurements.

Three samples - GFRP PA12, GFRP QUADRAXIAL, and GFRP 913 CROSSPLY $0-90$ - show significant transmittance in the range from $1.0 \mu \mathrm{m}$ to $2.3 \mu \mathrm{m}$. The other four samples-CFRP SE84 CROSSPLY, CFRP SE84, GFRP MTM28+-55, and CFRP SE84 QI-show no transmittance over the whole spectral range.

The results of the emissivity test revealed that emissivity depends on the material used: the samples made of GFRPs have a higher and spectrally less structured emis- 
sivity in the wavelength range from $5 \mu \mathrm{m}$ to $25 \mu \mathrm{m}$ than the samples made of CFRPs in the same range.

On the other hand, the three partially transparent GFRP samples show a significant structure in their spectrally resolved emissivity values; they also show the expected decrease in their emissivity at wavelengths under $2.3 \mu \mathrm{m}$. The uncertainties achieved are below or close to the target value of 0.01 and represent a significant improvement over the past data situation.

These optical properties were successfully used to evaluate the data from applying different active thermography techniques [14] for the quantification of artificial and natural defects in fiber-reinforced composites within the scope of the EMRP Project titled "Validated Inspection Techniques for Composites in Energy Applications" (VITCEA).

Acknowledgments This work was part of the ENG57 VITCEA project in the European Metrology Research Programme (EMRP) funded by EURAMET/NMS. We gratefully acknowledge the provision of the GFRP and CFRP samples by the partner organizations within the VITCEA project, represented by C. Maierhofer, R. Krankenhagen, M. Röllig, and S. Riemer from BAM, and by M. Gower, G. Baker, and M. Lodeiro from NPL.

Open Access This article is distributed under the terms of the Creative Commons Attribution 4.0 International License (http://creativecommons.org/licenses/by/4.0/), which permits unrestricted use, distribution, and reproduction in any medium, provided you give appropriate credit to the original author(s) and the source, provide a link to the Creative Commons license, and indicate if changes were made.

\section{References}

1. P.K. Mallick, Fiber-reinforced composites: materials, manufacturing, and design, 3rd edn. (Routledge, Taylor \& Francis Group, 2007)

2. ENG57 VITCEA-Validated inspection techniques for composites in energy applications. EMRPProject. http://projects.npl.co.uk/vitcea/

3. C. Maierhofer, R. Krankenhagen, M. Röllig, S. Riemer, M. Gower, G. Baker, M. Lodeiro, L. Knazovicka, A. Blahut, C. Monte, A. Adibekyan, B. Gutschwager, Characterisation of artificial and natural defects in fibre reinforced plastics designed for energy applications using active thermography, in 19th World conference on non-destructive testing, Munich, Germany (2016). http://www.ndt.net/article/ wcndt2016/papers/we2i4.pdf

4. M. Gower, M. Lodeiro, A. Aktas, R. Shaw, C. Maierhofer, R. Krankenhagen, S. Augustin, M. Röllig, L. Knazovická, A. Blahut, C. Monte, R. Judaschke, D. Segur, Design and manufacture of reference and natural defect artefacts for the evaluation of NDE techniques for fibre reinforced plastic (FRP) composites in energy applications, in 19th World conference on non-destructive testing, Munich, Germany (2016). http://www.ndt.net/article/wcndt2016/papers/we1e4.pdf

5. C. Maierhofer, M. Röllig, R. Krankenhagen, P. Myrach, Comparison of quantitative defect characterization using pulse-phase and lock-in thermography. Appl. Opt. 55, D76-D86 (2016). https://doi.org/ 10.1364/AO.55.000D76

6. V. Le Louët, B. Rousseau, S. Le Corre, N. Boyard, X. Tardif, J. Delmas, D. Delaunay, Directional spectral reflectivity measurements of a carbon fibre reinforced composite up to $450{ }^{\circ} \mathrm{C}$. Int. J. Heat Mass Transf. 112, 882-890 (2017). https://doi.org/10.1016/j.ijheatmasstransfer.2017.04.125

7. J.A. Hubbard, A.L. Brown, A.B. Dodd, S. Gomez-Vasquez, C.J. Ramirez, Carbon fiber composite characterization in adverse thermal environments. Report No. SAND2011-2833 (2011). http://prod. sandia.gov/techlib/access-control.cgi/2011/112833.pdf

8. Joint Committee for Guides in Metrology (JCGM), Evaluation of measurement data-guide to the expression of uncertainty in measurement (Online) (2008). http://www.bipm.org/en/committees/jc/ $\mathrm{jcgm} /$ 
9. C. Monte, B. Gutschwager, S.P. Morozova, J. Hollandt, Int. J. Thermophys. 30, 203-2019 (2009). https://doi.org/10.1007/s10765-008-0442-9

10. A. Adibekyan, C. Monte, M. Kehrt, B. Gutschwager, J. Hollandt, Int. J. Thermophys. 36, 283-289 (2015). https://doi.org/10.1007/s10765-014-1745-7

11. C. Monte, J. Hollandt, High Temp. High Press. 39, 151-164 (2010)

12. C. Monte, J. Hollandt, Metrologia 47, 172-181 (2010). https://doi.org/10.1088/0026-1394/47/2/s 14

13. A. Adibekyan, E. Kononogova, C. Monte, B. Gutschwager, J. Hollandt, Emissivity, reflectivity and transmissivity of semitransparent fibre reinforced plastic composites (2018). https://www.ndt.net/ article/dgzfp-irt-2017/papers/17.pdf

14. C. Maierhofer, R. Krankenhagen, M. Röllig, S. Unnikrishnakurup, C. Monte, A. Adibekyan, B. Gutschwager, L. Knazowicka, A. Blahut, M. Gower, M. Lodeiro, G. Baker, A. Aktas, Einfluss thermischer und optischer Materialeigenschaften auf die Charakterisierung von Fehlstellen in Faserverbundwerkstoffen mit aktiven Thermografieverfahren, Temperatur 2017, Technisches Messen, ISSN (Online) 2196-7113, ISSN (Print) 0171-8096 (2017). https://doi.org/10.1515/teme-2017-0078

Publisher's Note Springer Nature remains neutral with regard to jurisdictional claims in published maps and institutional affiliations

\section{Affiliations}

\section{A. Adibekyan ${ }^{1} \cdot$ E. Kononogova ${ }^{1}$. C. Monte ${ }^{1} \cdot \mathrm{J}$ Hollandt $^{1}$}

$凶 \quad$ A. Adibekyan

albert.adibekyan@ptb.de

1 Physikalisch-Technische Bundesanstalt (PTB), Berlin, Germany 